\title{
Design \& Simulation of Fuzzy Logic Based Speed Control of SPWM Inverter-fed Electrical Vehicle with Induction Motor taking Core loss and Stray Load Losses into Account
}

\author{
Sadia Nahar, Md. Kamrul Hassan, Mohammad Abdul Mannan
}

\begin{abstract}
In modern technology electrical differentials to design Electrical Vehicle (EV) are getting popular for its simplicity, faster response, accurate control capability and other facility. The controller design for the distinctive motors is a captivating and challenging work to acquire sought execution appropriately. For this different kind of controller is used to get accurate results. For Induction Motor (IM) it is very important to control the speed and torque to get smooth control application. Field Oriented Control (FOC) aids the factor and empowers independent control of speed and torque by building up an autonomous relationship is created due to consideration of core loss and stray load losses while modeling Induction Motor which is neglected at most of the works. Here, Induction Motor is modeled with the Fuzzy Logic Controller for more accuracy and simplicity and the Sinusoidal Pulse Width Modulation (SPWM) is utilized as a part of the structure to investigate the performance of IM under various source parameters such as diversity of voltage, frequency and so forth. MATLAB/Simulink is used to execute the simulation results.
\end{abstract}

Keywords-Electrical Vehicle; Induction Motor; Fuzzy Logic Controller; Sinusoidal Pulse Width Modulation; Field Oriented Control;

\section{INTRODUCTION}

With the height of technological headway in current time, the automotive engineering faced a lot progressive dealing of side by side innovations. The developing concern with the unfriendly impacts of hydrocarbon-related vehicle, electronic vehicles have benefitted prominent position in cutting edge time. Over the time progression in innovation has occurred; manufacturers incorporate more and more attractive than before [1]. So the attention concentrated on autonomous driving wheel engine on the back wheel to supplanted Mechanical Differential (MD) into Electrical Differential (ED) in EV [1, 2]. ED constitutes an innovative advancement in vehicle design decreasing the vehicle mass and improving the overall system reliability and efficiency

Sadia Nahar is a student of Masters in Engineering at EEE Dept. of American International University-Bangladesd (AIUB).

Email: aidas_rahan@yahoo.com

Md. Kamrul Hassan is an Associate Professor at EEE Dept. of American International University-Bangladesh.

Mohammad Abdul Mannan is a Professor and Head (UG Program) at EEE Dept. of American International University-Bangladesh.
$[2,3]$. ED's principle feature is the robust improvement against system uncertainties and street conditions. ED can control both the driving wheel independently to turn at different speed in any curve and distribute the power to each motor according to the steering angle [3].

Induction Motor is very popular in the industrial applications because of its low maintenance and cost, simplicity of design, robustness, good self starting, high efficiency, small inertia and absence of the controller brooms system [4-6]. Field Oriented Control (FOC) accompanies the state of legitimate modeling of IM. Induction motors are modeled from various perspectives. Each of it has claim favorable position and burden. In any case, to acquire a consummately working control scheme, it is vital that the system under supervision is modeled appropriately so that maximum of its behavior can be anticipated.

Induction motor models are considered without taking the core loss and stray load losses into account in most of works [69]. Therefore, greater portion of the speed controllers designed so far could not achieve expected performance and hence failed to produce satisfactory output. However, some recent work takes core loss and stray load loss into account [10-13]. These are so far the most effective models of induction motor which can be expected to work with accuracy.

In order to achieve the same performance of DC machine from IM, the rotor flux and torque are decoupled in terms of stator current components neglecting the core loss and stray load losses. These losses of induction motor are very common and may not be negligible to achieve precise industrial application. To design the precise control strategies of an IM considering core loss and stray load losses different mathematical model based on the equivalent circuit has been reported in literatures. Core loss was represented by an equivalent resistance in parallel with the magnetizing branch [10-13] and stray load loss was represented by a resistance in parallel with the secondary leakage inductance [10-13]. The 
Fuzzy-Logic Control (FLC) is seemed to be a suitable controller in terms of high dynamic response under the variation of load torque and parameters $[12,13]$. The FLC get its popularity due to its simple linguistic rules like human thinking. It does not need any precise mathematical explanations to obtain a decision inference. The FLC requires only a qualitative knowledge which not only makes to controller easy to use but also easy to design. So it eases obtaining speed controller for an IM.

This paper proposes a fuzzy logic control application of an electrical differential system for an EV propelled by two IM (One for each rear wheel). Overall system including FLC with IM taking core loss and stray load losses into account is implemented in MATLAB Simulink.

\section{DY NAMIC \& STATE SPACE MODEL OF INDUCTION MOTOR}

The dynamic modeling of an IM taking core loss and stray load losses into account in synchronously rotating $d-q$ axis reference frame is shown in Fig. 1. The reference frame is rotating of an electrical angular velocity $\omega_{r}$. Hysteresis loss and eddy current loss are the two components of core loss but for simplicity, the components of core loss are represented by a single quantity with a constant value of $R_{c}$ and stray load losses are shown with a constant value $R_{s t}$ as shown in Fig. 1.
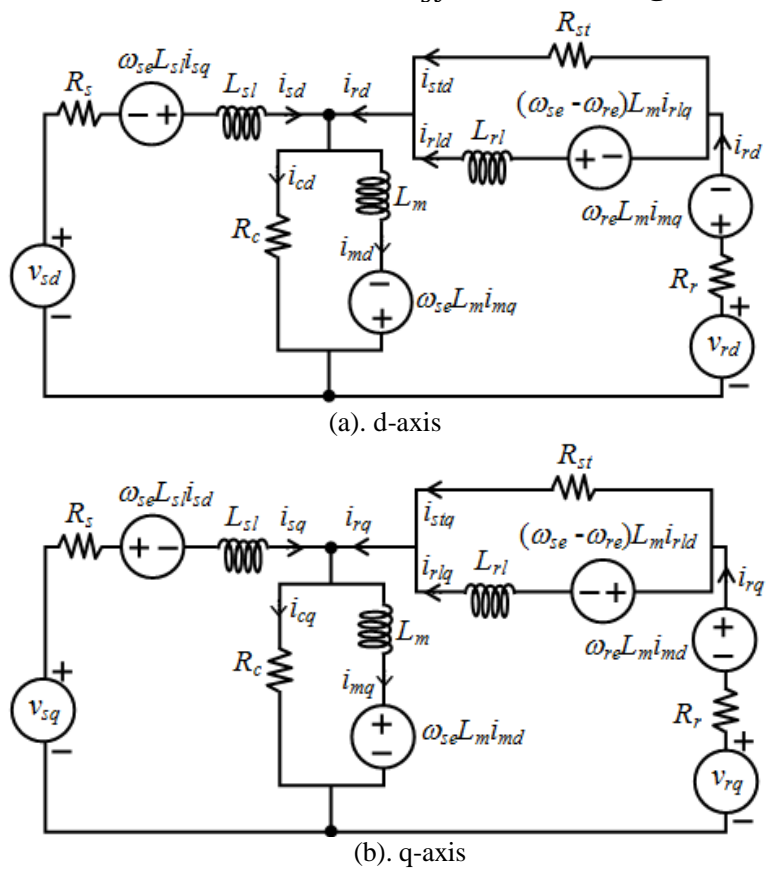

Fig. 1: Equivalent Circuit of IM model.

According to Fig. 1 the d-q axis stator voltage of an IM as follows:

$$
\begin{gathered}
v_{s}=R_{s} i_{s}+\left(L_{s l} p i_{s}+j \omega_{s e} L_{s l} i_{s}\right)+\left(L_{m} p i_{m}+j \omega_{s e} L_{m} i_{m}\right) \\
\begin{aligned}
v_{r}=R_{r} i_{r}+ & \left(L_{r l} p i_{r l}+j\left(\omega_{s e}-\omega_{r e}\right) L_{r l} i_{r l}\right) \\
& +\left(L_{m} p i_{m}+j \omega_{s e} L_{m} i_{m} L_{s l}\right) \\
& -j \omega_{r e} L_{m} i_{m} p i_{r}
\end{aligned}
\end{gathered}
$$

For squirrel cage motor,

$$
\begin{aligned}
& \phi_{s}=L_{s l} \boldsymbol{i}_{s}+L_{m} \boldsymbol{i}_{m} \\
& \phi_{r}=L_{r l} \boldsymbol{i}_{r}+L_{m} \boldsymbol{i}_{m}
\end{aligned}
$$

$$
\begin{aligned}
& R_{c} i_{c}=L_{m} \frac{d i_{m}}{d t}+j \omega_{s} L_{m} i_{m} \\
& R_{s t} i_{s t}=L_{r l} \frac{d i_{r l}}{d t}+j \omega_{s l} L_{r l} i_{r l} \\
& i_{s}+i_{r}=i_{c}+i_{m} \\
& T_{e}=\left(\frac{3}{2}\right) P_{n}\left(\phi_{q r} \boldsymbol{i}_{d r}-\phi_{d r} \boldsymbol{i}_{q r}\right) \\
& \boldsymbol{i}_{s t}=\boldsymbol{i}_{r}-\boldsymbol{i}_{r l}
\end{aligned}
$$

In the above equations, $v_{S}$ and $v_{r}$ are $\mathrm{d}$ and $\mathrm{q}$ axis stator voltages; $i_{s d}$ and $i_{s q}$ indicate $\mathrm{d}$ and q axes stator currents;,$i_{d r}$ and $i_{q r}$ indicate $\mathrm{d}$ and $\mathrm{q}$ axes rotor currents; and $\phi_{d r}$ and $\phi_{q r}$ indicate $\mathrm{d}$ and $\mathrm{q}$ axes rotor fluxes; $\omega_{S}$ and $\omega_{s l}$ indicate primary and slip angular frequencies; $R_{s}, R_{r}$ and $R_{s t}$ indicate stator, rotor resistances and stray load loss resistance; $L_{s l}, L_{m}, L_{r l}$ indicate stator leakage, mutual, rotor leakage inductances respectively; $T_{e}$ and $T_{L}$ indicate electromagnetic and load torques; $J, D$ and $P_{n}$ indicate moment of inertia, friction coefficient and number of pole pair.

Using equations (1-9) the first order state space equation can be written as:

$$
\begin{gathered}
\frac{d \mathbf{i}_{s}}{d t}=-K_{20} \boldsymbol{i}_{s}-K_{21} \boldsymbol{i}_{m}-K_{22} \Phi_{r}-j \omega_{s e} \boldsymbol{i}_{s}- \\
j K_{23} \omega_{r e} \boldsymbol{i}_{m}+K_{19} \boldsymbol{v}_{s}-K_{24} \boldsymbol{v}_{r} \\
\frac{d \mathbf{i}_{m}}{d t}=K_{14} \boldsymbol{i}_{s}+K_{15} \boldsymbol{i}_{m}+K_{16} \Phi_{r}+j K_{17} \omega_{r e} \boldsymbol{i}_{m}- \\
j \omega_{s e} \boldsymbol{i}_{m}+K_{18} \boldsymbol{v}_{r} \\
\frac{d \Phi_{r}}{d t}=K_{25} \boldsymbol{i}_{s}-K_{26} \boldsymbol{i}_{m}-K_{27} \Phi_{r}-j K_{28} \omega_{r} \boldsymbol{i}_{m}- \\
j \omega_{s l} \Phi_{r}+K_{19} \boldsymbol{v}_{r} \\
\frac{d \omega_{r e}}{d t}=-K_{30} \omega_{r e}+K_{31}\left(T_{e}-T_{L}\right) \\
T_{e}=\left(\frac{3}{2}\right) P_{n}\left\lfloor\boldsymbol{i}_{r d} \Phi_{r q}-\boldsymbol{i}_{r q} \Phi_{r d}\right\rfloor
\end{gathered}
$$

Here,

$$
\begin{aligned}
K_{8}= & \frac{R_{c}}{R_{r s c}} ; K_{9}=\frac{R_{c} L_{r l}-R_{s t} L_{m}}{R_{r s c} L_{r l}} ; K_{10}=\frac{R_{s t}}{R_{r s c} L_{r l}} ; \\
K_{11}= & \frac{L_{m}}{R_{r s c}} ; K_{14}=\frac{\left(R_{r s c}-R_{c}\right) R_{c}}{R_{r s c} L_{m}} ; \\
K_{15}= & \frac{\left(R_{c} L_{r l}-R_{s t} L_{m}-R_{r s c} L_{r l}\right) R_{c}}{R_{r s c} L_{r l} L_{m}} \\
K_{16}= & \frac{R_{c} R_{s t}}{R_{r s c} L_{r l} L_{m}} ; K_{17}=\frac{R_{c}}{R_{r s c}} ; \\
K_{18}= & \frac{R_{c}}{R_{r s c} L_{m}} ; K_{19}=\frac{1}{L_{s l}} ; \\
K_{20}= & \frac{\left(R_{s} R_{r s c}+R_{r} R_{c}+R_{s} R_{c}\right)}{R_{r s c} L_{s l}} ; \\
K_{21}= & \frac{R_{c}}{L_{s l}}\left(\frac{R_{c} L_{r l}-R_{s t} L_{m}}{R_{r s c} L_{r l}}-1\right) ;
\end{aligned}
$$


$K_{22}=\frac{R_{c} R_{s t}}{R_{r s c} L_{r l} L_{s l}} ; K_{23}=\frac{R_{c} L_{m}}{R_{r s c} L_{s l}} ;$

$K_{24}=\frac{R_{c}}{R_{r s c} L_{s l}} ; K_{25}=\frac{R_{r} R_{c}}{R_{r s c}}$;

$K_{26}=\frac{R_{r}\left(R_{c} L_{r l}-R_{s t} L_{m}\right)}{R_{r s c} L_{r l}} ; K_{27}=\frac{R_{r} R_{s t}}{R_{r s c} L_{r l}} ;$

$K_{28}=\frac{R_{r} L_{m}}{R_{r s c}} ; K_{29}=1-\frac{R_{r}}{R_{r s c}} ; K_{30}=\frac{B_{m}}{J_{m}} ; K_{31}=$

$\frac{P_{n}}{J_{m}} ; K_{32}=\frac{3}{2} P_{n} K_{31}$

\section{Electrical Vehical Mechanical LoAd}

Here, the load is the vehicle and it is characterized by different resistive torques. The vehicle torques are given below $[14,15]$ :

The rolling force and torque can be given as:

$$
\left\{\begin{array}{c}
F_{\text {roll }}=M g f_{r} \\
T_{\text {roll }}=M g f_{r} R_{\omega}
\end{array}\right.
$$

The aerodynamic force and torque is:

$$
\left\{\begin{array}{c}
F_{\text {aero }}=\frac{1}{2} \rho A_{f} C_{d} v_{h}^{2} \\
T_{\text {aero }}=\frac{1}{2} \rho A_{f} C_{d} v_{h}^{2} R_{\omega}
\end{array}\right.
$$

The slope force and torque can be given as:

$$
\left\{\begin{array}{c}
F_{\text {slope }}=M g \sin \beta \\
T_{\text {slope }}=M g \sin \beta R_{\omega}
\end{array}\right.
$$

The total resistive torque can be defined as:

$$
T_{\text {res }}=T_{\text {roll }}+T_{\text {aero }}+T_{\text {slope }}
$$

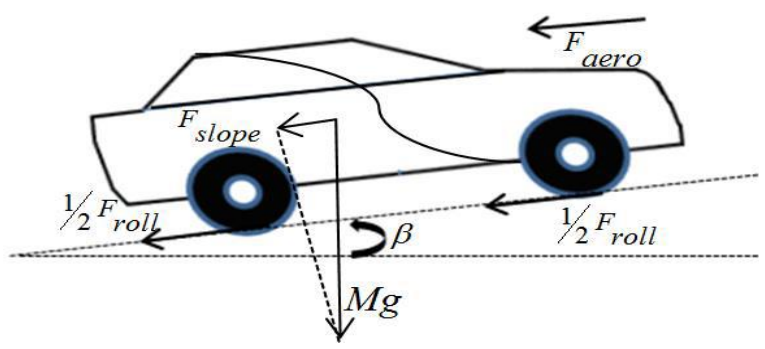

Fig. 2: Forces Acting on a Vehicle along a Slope Path.

\section{ELECTRONIC DIFFERENTIAL MODELING}

The proposed control system principle could be summarized as follows: 1) Speed control is used to control each motor torque; 2) The speed of each rear wheel is controlled using speed difference feedback. Here, the two rear wheels are driven by two separate motors.

For Steering condition, when the vehicle need to turn right then the left wheels speed will be higher than the right wheel and vice versa.
Here, the Ackermann-Jeanutaud steering model driving trajectory is used for the vehicle systems model analysis [15]. $v_{L}$ is the linear speed of the left wheel drive; $v_{R}$ is the right wheel drive. The linear speed of each wheel drive is expressed as a function of the vehicle angular speed and the radius of the curve, according to Fig. 3.

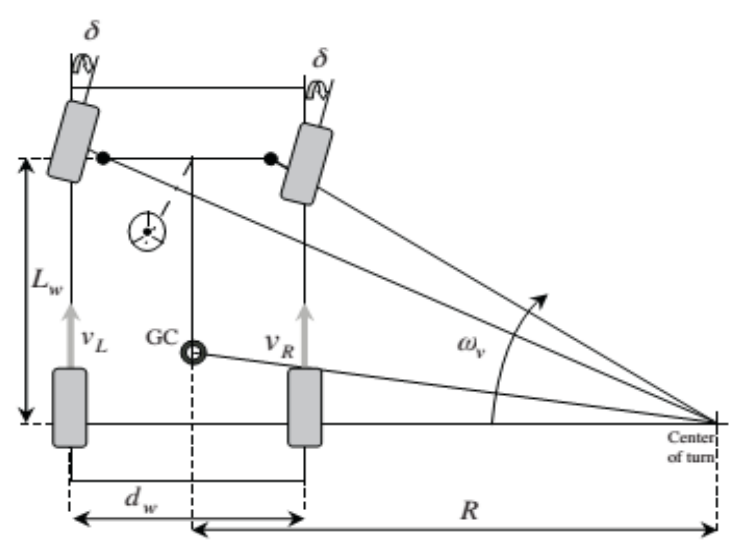

(a)

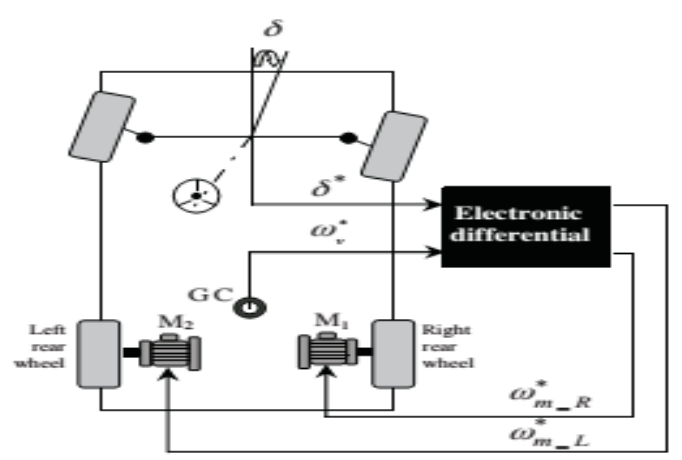

(b)

Fig. 3: (a) Structure of Electronic Differential. (b) Design Model for Vehicle Structure Driven in a Curve

$$
\begin{aligned}
& v_{L}=\omega_{v}\left(R+\frac{d_{\omega}}{2}\right) \\
& v_{R}=\omega_{v}\left(R-\frac{d_{\omega}}{2}\right)
\end{aligned}
$$

The curve radius is related to the wheelbase and steering angle:

$$
R=\frac{L_{\omega}}{\tan \delta}
$$

Substituting Eq. (18) into Eqs. (16) and (17), we obtain the angular speed in each wheel drive:

$$
\begin{aligned}
& \omega_{r L}=\frac{L_{\omega}+1 / 2 d_{\omega} \tan \delta}{L_{w}} \omega_{v} \\
& \omega_{r L}=\frac{L_{\omega}-1 / 2 d_{\omega} \tan \delta}{L_{w}} \omega_{v}
\end{aligned}
$$

The difference between the angular speeds of the wheel drives is expressed by the relation:

$$
\Delta \omega=\omega_{l R}-\omega_{r R}=\frac{\left(d_{\omega} \cdot \tan \delta\right)}{L_{\omega}} \omega_{v}
$$

The direction of turn of an EV can be determined by the applied steering angle $(\delta)$ as follows:

$$
\begin{aligned}
& \delta>0=\text { Turnright } \\
& \delta=0=\text { Straightahead } \\
& \delta<0=\text { Turnleft }
\end{aligned}
$$


When the steering angle is applied the speed of inner wheel is reduced and the speed is increased of outer wheel. The driving wheel reference angular speeds are calculated by:

$$
\begin{aligned}
& \omega_{l R}^{*}=\omega_{v}+\frac{\Delta \omega}{2} \\
& \omega_{r R}^{*}=\omega_{v}-\frac{\Delta \omega}{2}
\end{aligned}
$$

The speed references of the two motors are:

$$
\begin{gathered}
\omega_{l m}^{*}=k_{g e a r} \omega_{l R}^{*} \\
\omega_{r m}^{*}=k_{g e a r} \omega_{r R}^{*}
\end{gathered}
$$

Where, $k_{\text {gear }}$ is the gearbox ratio.

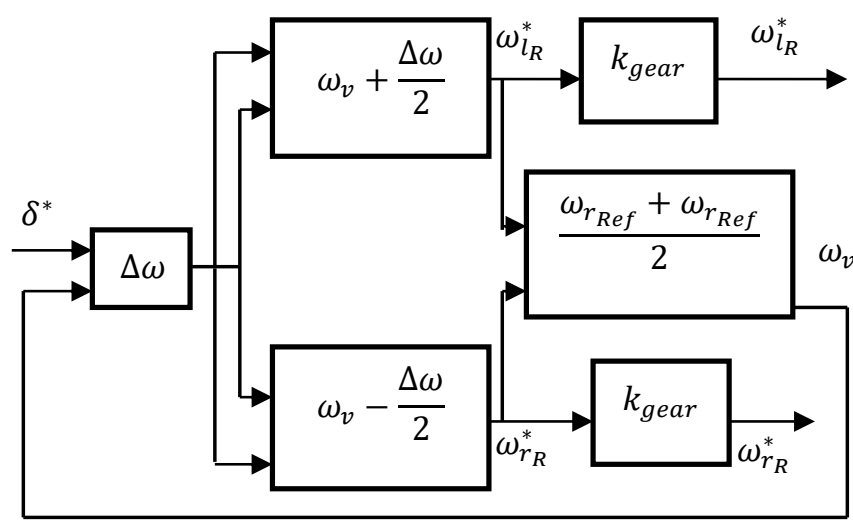

Fig. 4: Block Diagram to Show the Use of the Electronic Differentia.

\section{Fuzzy Logic CONTROLLER}

One reason for the ubiquity of Fuzzy Logic Controllers (FLC) is it's logical similarity to a human operator. Not like other control systems, this is less difficult as there is no complex mathematical learning required. The FLC requires only qualitative information of the framework subsequently making the controller simple to use, as well as to design.

Fig. 5 shows the simplified block diagram of FLC. Three essential parts of FLC are:

\section{A. Fuzzification:}

The fuzzification step converts the numerical input variables into linguistic variables by the fuzzifier. The controllers input linguistic variables available are the difference of the actual speed from the desired or reference speed, $e_{\omega}(k)$ and the difference of speed error, $\Delta e_{\omega}(k)$ and the first difference of magnetizing $q$-axis current, $\Delta i_{m q}^{*}$, is considered as the output linguistic variable. To ease the equations, the input and output are scaled with different coefficients these are: $K_{\omega}$ error of speed; $K_{e}$ change of error of speed and $K_{i}$ first difference of magnetizing q-axis current. Here the scaling factors are considered as constant and are selected by trial and error.

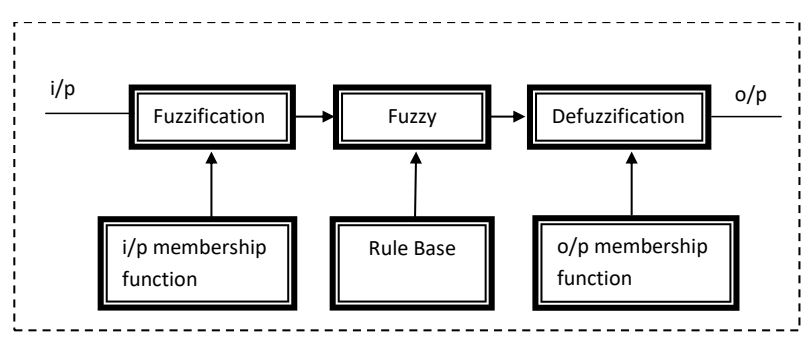

Fig. 5: Simplified Block Diagram of Fuzzy logic Controller.

AJSE Vol:17, Issue:1, pp 7 - 12

\section{B. Rule Base:}

The fuzzy mapping of the input variables to the output is represented to fuzzy IF-THEN rules of the following form:

$$
\begin{aligned}
& \text { If }\left\langle e_{\omega}^{n} \text { is } N\right\rangle \text { and }\left\langle\Delta e_{\omega}^{n} \text { is } N\right\rangle \text { Then }\left\langle\Delta i_{m q}^{n} \text { is } S\right\rangle \\
& \text { If }\left\langle e_{\omega}^{n} \text { is } P\right\rangle \text { and }\left\langle\Delta e_{\omega}^{n} \text { is } Z\right\rangle \text { Then }\left\langle\Delta i_{m q}^{n} \text { is } B\right\rangle
\end{aligned}
$$

The entire rule base is given in Table I. There are total 49 rules to achive desired speed trajectory.

\section{Interface and Defuzzification:}

The Inference system provides fuzzy values of $\Delta i_{m q}^{*}$ from the rule base in Table $\mathbf{I}$ and then crisp numerical value of $\Delta i_{m q}^{*}$ is obtained by using defuzzification procedure. Here it is done with the most popular method of inference and difuzzification Mamdani's max-min (or sum-product) composition with center of gravity method.

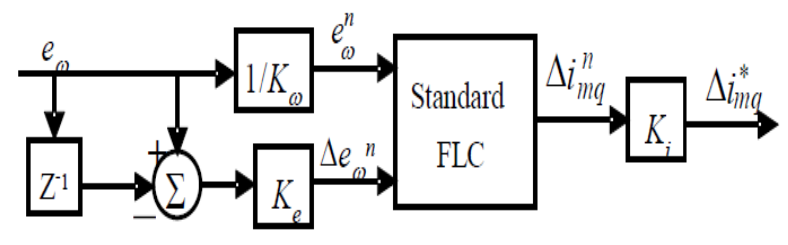

Fig. 6: Scheme structure of the proposed FLC.

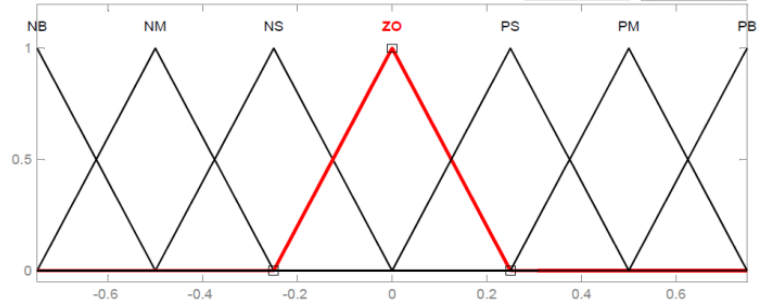

Fig. 7: Fuzzy sets and their corresponding membership function.

\begin{tabular}{|c|l|l|l|l|l|l|l|l|}
\multicolumn{8}{|c|}{ TABLE I. FUZZY RULES } \\
\hline \multicolumn{1}{|c|}{$\Delta i_{m q}^{*}$} & NB & NM & NS & ZO & PS & PM & PB \\
\hline \multirow{3}{*}{$e_{\omega}^{n}$} & NB & NB & NB & NM & NM & NS & NS & ZO \\
\cline { 2 - 9 } & NM & NB & NM & NM & NS & NS & ZO & PS \\
\cline { 2 - 9 } & NS & NM & NM & NS & NS & ZO & PS & PS \\
\cline { 2 - 9 } & ZO & NM & NS & NS & ZO & PS & PS & PM \\
\cline { 2 - 9 } & PS & NS & NS & ZO & PS & PS & PM & PM \\
\cline { 2 - 9 } & PM & NS & ZO & PS & PS & PM & PM & PB \\
\cline { 2 - 9 } & PB & ZO & PS & PS & PM & PM & PB & PB \\
\hline
\end{tabular}

The 49 rules shown in tabular form are written in the program according to the syntax provided by MATLAB. The document is saved with the extension '.fis'

\section{SPWM INVERTER DESIGN}

In the Sinusoidal Pulse-Width-Modulation (SPWM) modulation technique, the width of pulse is varied in proportion to the amplitude of a sine-wave evaluated at the center of the same pulse [16]. The gating signals are generated by comparing 
a sinusoidal reference signal of frequency, with a triangular carrier wave of frequency. Here, the reference voltages $U_{a}, U_{b}$, $\mathrm{U}_{\mathrm{c}}$ were taken from the controller to compare with triangular signal according to the Sinusoidal Pulse Width Modulation (SPWM) Techniques. Fig. 8 shows the pulses $S_{a}, S_{b}$ and $S_{c}$ which generated by comparing the voltages $U_{a}, U_{b}, U_{c}$ with triangular wave.

The desired Voltages $\mathrm{V}_{\mathrm{a}}, \mathrm{V}_{\mathrm{b}}, \mathrm{V}_{\mathrm{c}}$ can calculated based on the generated gate pulses using following equations:

$$
\left[\begin{array}{c}
V_{\mathrm{a}} \\
\mathrm{V}_{\mathrm{b}} \\
\mathrm{V}_{\mathrm{c}}
\end{array}\right]=\frac{\mathrm{U}_{\mathrm{dc}}}{2}\left[\begin{array}{ccc}
2 & -1 & -1 \\
-1 & 2 & -1 \\
-1 & -1 & 2
\end{array}\right]\left[\begin{array}{l}
\mathrm{S}_{\mathrm{a}} \\
\mathrm{S}_{\mathrm{b}} \\
\mathrm{S}_{\mathrm{c}}
\end{array}\right]
$$

In this paper Matlab/Simulink in used to solve those equations to get desired voltages.

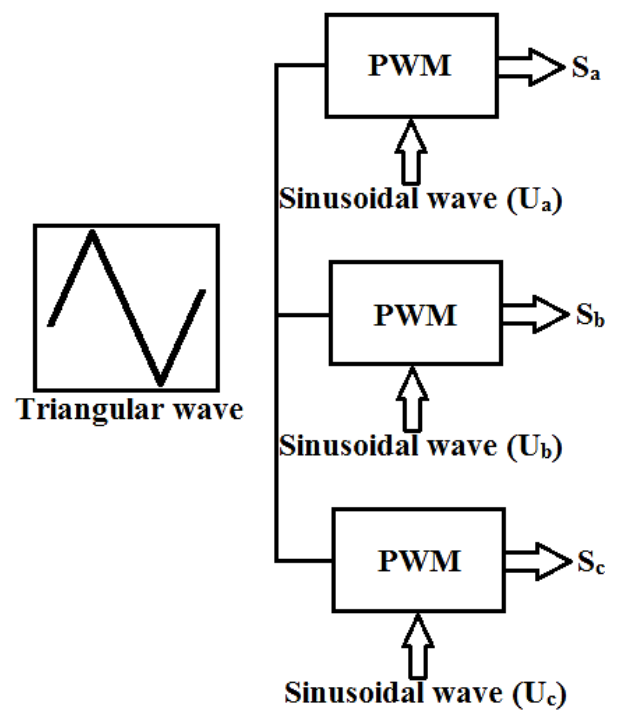

Fig. 8: Block Diagram of Pulse Generation for SPWM Inverter.

\section{Simulation \& RESUlts}

The performance of the proposed control system is simulated using Matlab/Simulink software. The used parameters for simulation are shown in Appendix 1 and Appendix 2. For this simulation the sampling time is chosen to be $100 \mu \mathrm{s}$. the desired goal of this proposed scheme is to see the performance for slope road condition.

\section{A. Slope (up-hill and down-hill) Road Condition}

Fig. 9 and Fig. 10 show the transient simulation results of speed (Load) and torque (Electromagnetic Torque) for the slope condition. Here, the vehicle is considered to be running on uphill and down-hill condition. When the vehicle runs in up-hill condition then the slope torque is positive and overall torque is increased. In the Fig. 10 (a) and (b) at $t=2.5 \mathrm{~s}$, the vehicle is running uphill so the both motors torque increases. Again when the vehicle runs in down-hill condition then the slope torque is negative and overall torque is decreased. Like the Fig. 10 (a) and (b) shows at $\mathrm{t}=6 \mathrm{~s}$, the vehicle goes down-hill so the torque of the both motor decreases. When the vehicle goes to up-hill direction, the load torque increased as shown in Fig. 10 (a) and (b), and due to the increase of load torque the speed is fall down as shown in Fig. 9 (a) and (b) at $t=2.5 \mathrm{~s}$. Similar to that when the torque is decreased means the vehicle is going down-hill the speed of the both vehicle increased at $t=6 \mathrm{~s}$.
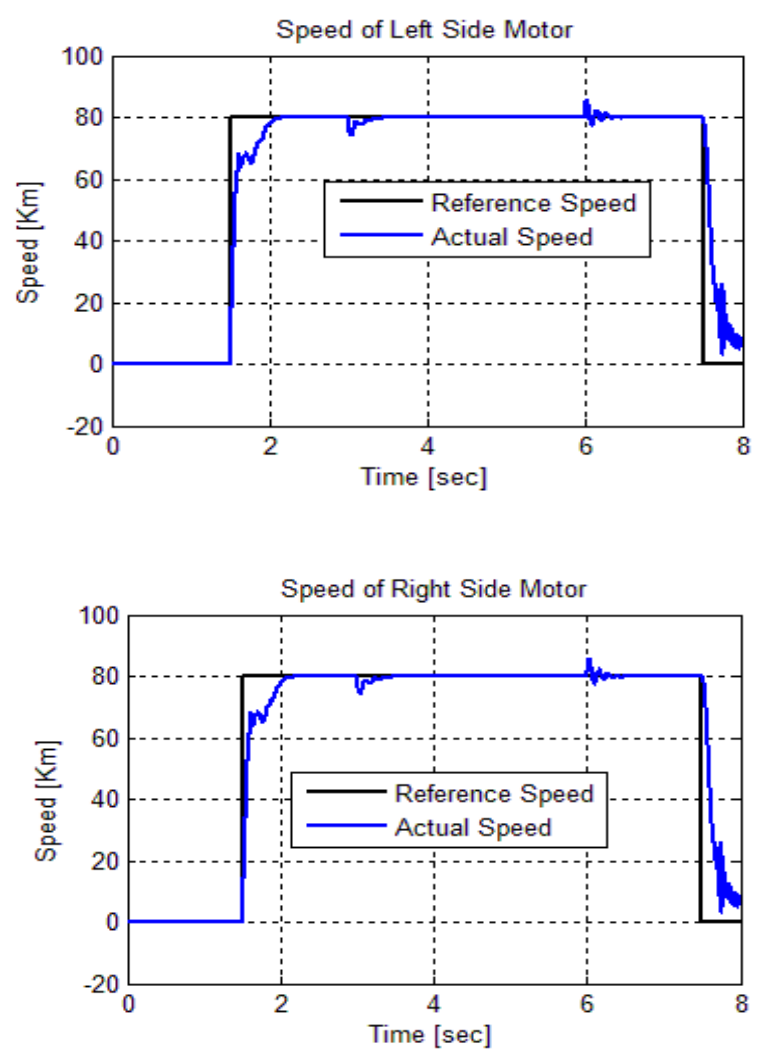

Fig: 9. a: Transient Response of Left Motor Speed for Sloped Road Condition b: Transient Response of Right Motor Speed for Sloped Road Condition
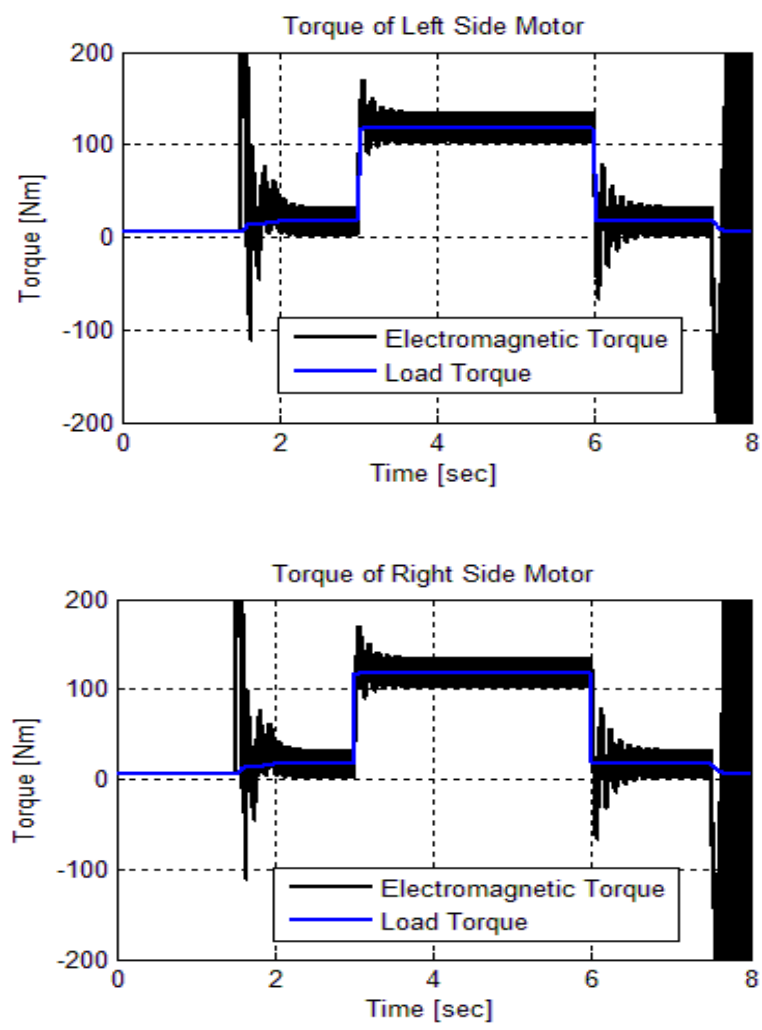

Fig. 10. a: Transient Response of Left Motor Torque for Sloped Road Condition

b: Transient Response of Right Motor Torque for Sloped Road Condition 


\section{VIII.CONCLUSION}

This paper has discussed about the model of an Electrical Vehicle, including model of IM taking core loss and stray load losses with a Fuzzy Logic Controller. The whole simulation is done incorporate with SPWM in Matlab environment. The proposed method shows the results for slope road condition only. The proposed controller is skilled to give a superior performance both at transient and steady state condition. It overcomes the problem of overshoot and load torque change that was present in case of PI controller. Also it comforts the designer since it is free from tiring mathematical expressions. More works should be done to simulate the other road conditions on this proposed method.

\section{APPENDIX 1. RATINGS AND PARAMETERS OF INDUCTION MOTOR}

$3 \mathrm{hp}, 1430 \mathrm{rpm}, 14.96 \mathrm{~N}-\mathrm{m}, 4$ pole, $50 \mathrm{~Hz}$,

$R s=85.1 \mathrm{~m} \Omega, R r=65.8 \mathrm{~m} \Omega, R c=812 \Omega, \mathrm{R}_{\mathrm{st}}=5.2 \Omega$

$L s l=2.3 \mathrm{mH}, \mathrm{Lrl}=1.5 \mathrm{mH}, L m=29.1 \mathrm{mH}$, $J=0.23 \mathrm{Kg} \cdot \mathrm{m}^{2}$

\section{APPENDIX 2. EV MECHANICAL AND AERODYNAMIC} PARAMETERS

$$
\begin{gathered}
\mathrm{M}=1300 \mathrm{~kg} ; \mathrm{A}_{\mathrm{f}}=2.6 \mathrm{~m}^{2} ; \mathrm{R}_{\mathrm{w}}=0.32 \mathrm{~m} ; \\
\mathrm{C}_{\mathrm{ad}}=0.32 ; \eta_{\mathrm{g}}=0.98 ; \mathrm{v}=22.2 \mathrm{~m} / \mathrm{s} ; \\
\mathrm{g}=9.81 \mathrm{~m} / \mathrm{s}^{2} ; \rho=1.2 \mathrm{~kg} / \mathrm{m}^{2}
\end{gathered}
$$

\section{REFERENCES}

[1] Brahim Gasbaoui, Abdelfatah Nasri, Othmane Abdel Khalek, "An Efficiency PI Speed Controller for Future Vehicle in Several Topology", 9th International Conference Interdisciplinary in Engineering, 8-9 October 2015.

[2] Sumon Kumar Ghos, Mohammad Abdul Mannan, "Design and Analysis of Linear Quadratic Regulator for the application of EV Differential based on IPMSM", Journal of Control \& Instrumentation, May 2016.

[3] Mohammad Ashraful Alam, Mohammad Abdul Mannan, "Design and Analysis of EV Controller using IPMSM Taking Core Loss into Account", Journal of Control \& Instrumentation, Vol. 6, No. 2, 2015.

[4] P. Vas, "Electrical Machines and Drives: A Space-Vector Theory Approach", Clarendon Press, New York, 1992.

[5] F. Harashima, S. Kondo, K. Ohnishi, M. Kajita and M. Susono, "MultiMicroprocessor-Based Control System for Quick Response Induction Motor Drive", IEEE Transation Industrial Applications, Vol. 21, No. 3, 1985, pp 602-609.

[6] B. K. Bose: "Motion Control Technology-Present and Future," IEEE Transaction on Industrial Applications, Vol. 21, No. 6, 1985, pp. 1337 1342. doi:10.1109/TIA.1985.349587

[7] Suwankawin S, Sangwongwanich S, A Speed Sensorless IM Drive with Decoupling Control and Stability Analysis of Speed Estimation. IEEE T Ind Electron. 2002; 49(2): 444-455p.

[8] Orlowska-Kowalska T, Dybkowski M. Stator-Current-Based MRAS Estimator for a Wide Range Speed-Sensorless Induction-Motor. IEEE T Ind Electron. 2010; 57(4): 1296-1308p.

[9] Najafabadi TA, Salmasi FR, Jabehdar-Maralani. Detection and Isolation of Speed, DC-Link Voltage-, and Current-Sensor Faults Based on an Adaptive Observer in Induction-Motor. IEEE T Ind Electron. 2011; 58(5): 1662-1672p.

[10] Boldea I, Nasar SA. Unified Treatment of Core Losses and Saturation in the Orthogonal-axis Model of Electric Machines. IEEE Proc. Pt.B, 1987; 134: 355-363p.

[11] Emil Levi. Impact of Iron Loss on Behavior of Vector Controlled Induction Machine. IEEE T Ind Appl. 1995; 31: 1287-1296p.
[12] Levi E, Lamine A, Cavagnino A. Detuned Operation of Vector Controlled Induction Machines due to Stray Load Losses. Industry Applications Conference. 2005. Fourteenth IAS Annual Meeting. Conference Record. 2-6 Oct 2005; 1: 500-507p.

[13] Levi E, Lamine A, Cavagnino A. Impact of Stray Load Losses on Vector Control Accuracy in Current-Fed Induction Motor Drives. IEEE T Energy Conver. 2006; 21(2): 442-450p.

[14] Brahim Gasbaoui, Abdelfatah Nasri, "A Novel Multi-Drive Electric Vehicle System Control Based on Multi-Input Multi-Output PID Controller", SERBIAN JOURNAL OF ELECTRICAL ENGINEERING, Vol. 9, No.2, June, 2012

[15] J. A.Haddoun, M.Benbouzid, D.Diallo, "Modeling, Analysis and Neural Network Control of An EV Electrical Differential", IEEE Transactions, Vol. 55, No. 6, pp.2286-2294, June, 2008.

[16] Bimal K. Bose. Modern Power Electronics and Ac Drives. Prentice Hall; 2001

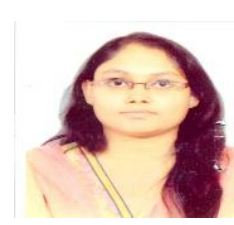

Sadia Nahar was born in Dhaka, Bangladesh on July 16, 1992. She received her B.Sc. Eng. Degree in EEE from American International UniversityBangladesh (AIUB), Bangladesh in 2014. At present, she is doing her Masters in Electrical \& Electronic Engineering in EEE Department of American International University-Bangladesh (AIUB), Bangladesh.

Her research interests are in the field of Power Electronics, Renewable Energy, Power System, Control System etc

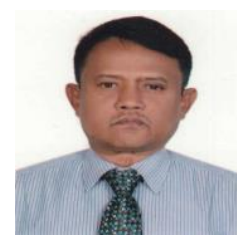

Dr. Md. Kamrul Hassan received his B.Sc. degree in Electrical and Electronic Engineering from Bangladesh University of Engineering and Technology, (BUET), Dhaka in 1987 and Dr. of Engineering degree in Plasma Science and Engineering (Plasma Deposition \& Electrical Characterization of Diamond-Like Carbon (DLC) Thin Films) from Kochi University of Technology, Japan, in 2007.He started his professional career as an Assistant Engineer (Electrical/Instrument) in Bangladesh Chemical Industries Corporation (BCIC) from September, 1988, became an Executive Engineer in 1997 During his job in BCIC, he also completed Post-Graduate Diploma in Industrial Management (PGDIM) in 1990 from Bangladesh Management Development Centre, Dhaka, Bangladesh. He also completed many training courses on different types of process control instrumentations including programmable logic controller (PLC) and programmable instruments during his job in BCIC from 1988 to 2003.

After having the Dr. of Engineering degree, he started his teaching career as an Assistant Professor in Electronic and Telecommunication Engineering (ETE) Department of Daffodil International University, Dhaka, Bangladesh in May, 2008 and he worked there till August, 2008. On September, 2008 he joined as a Faculty member of Electrical and Electronic Engineering (EEE) Department under Engineering Faculty, American International University-Bangladesh (AIUB). On May, 2009 he was appointed as an Assistant Professor of EEE Department, Faculty of Engineering, AIUB Currently he is an Associate Professor at the American International University-Bangladesh (AIUB). His present research interest includes Plasma Science, Nanotechnology, Electrical Characterization of Nanostructure Thin Films, and Solid state electronics, Materials science. Dr. Md. Kamrul Hassan is a Member of the Institution of Engineers Bangladesh (IEB).

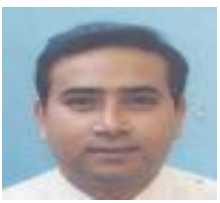

Mohammad Abdul Mannan was born in Laxmipur, Bangladesh on January 01, 1975. He received his B. Sc. Eng. Degree from Rajshahi University of Engineering and Technology (RUET former BITR), Bangladesh, in 1998, and Masters of Eng. and Dr. of Eng. degrees from Kitami Institute of Technology, Japan, in2003 and 2006 respectively all in Electrical Engineering. He then joined American International University Bangladesh (AIUB) as an Assistant professor. At present he is Professor \& serving as Under Graduate Head of EEE department in American International University- Bangladesh (AIUB). He is a member of the IEEE and IEB. His research interests include electric motor drive, power electronics, power system, wind generation system and control of electric motor, power electronic converters, power system, and wind generation system. 